Enletawa Journal n' ${ }^{\circ} .10 .2$

ISSN 2011 - 835X (printed)

ISSN 2463 - 1965 (online)

July - December - 2017, pp. 80-92

\title{
The Golden Mill ${ }^{1}$
}

\section{E1 Molino Dorado}

\author{
Mauricio Barrera Cárdenas ${ }^{2}$ \\ Horizons educative corporation - Sogamoso \\ mauros4@yahoo.com
}

Received: April 10, 2017

Accepted: May 19, 2017

How to cite this story (APA, 6th ed.): Barrera-Cárdenas, M. (2017). The Golden Mill. Enletawa Journal, 10 (2), 80 - 92

\section{The Golden Mill}

\section{Chapter 1}

The Bourdeur Family was a traditional family that lived in Tolouse, France in the 1870 's. Two brothers were descendants of this family. Reyner, was born in 1871, and his brother Victorine, was born in 1872. These children were raised during the boom of the industrial revolution, but each followed a different life path. Reyner was attracted to cartography, and Victorine decided to become a literature teacher.

During the 1890's, a French engineering company that was attempting to construct the Panama channel was facing unexpected problems. A strange and unknown fever was killing all the workers in that region. An adventurous French map designer, Reyner, decided to leave because a strange fever was killing all the members of the company.

1 Creative writing

2 Mauricio Barrera Cárdenas studied Modern Languages at Universidad Pedagógica y Tecnológica de Colombia, UPTC. He graduated in 2004. He finished his master's in language teaching at the same university in 2016. He directs an educational institution for work and human development called Horizons educative corporation in Sogamoso. He is a teacher of humanities at the Comfaboy School. He is also leading the project of the company Didactife life. His published researches are related to culture as well as his literary project that is based on rescuing and highlighting historical events from his Boyacá context. The Golden Mill is the first out of 7 future stories. 
Reyner decided to go to Bogotá, crossing the Atlantic Ocean and the Magdalena River to look for a better opportunity, to find a job, and to demonstrate his talent. Eventually Reyner, at 22 years old, was hired by the Colombian government. The boarders' office wanted to explore and design the condition of the departments inside the country of Colombia. Reyner was sent to study the boundaries of two departments: Boyacá and Meta. His duty was to determine the different borders and describe the geography of the mountains and landscapes.

The climate of these regions was very attractive for this adventurer, who was discovering the privileges and hospitality of these Colombian cultures. He was fascinated with the geography, food and landscapes of these regions. For 30 years he worked there. Despite this, his mind was always focused on a special region found in the department of Boyacá.

He discovered mythical places like the páramos, flat land valleys, geysers, and farms in this area. Throughout the years, Reyner grew accustomed to the nature and culture of the Eastern region of Co-

3 Images drawn by the author lombia. Meanwhile, the empires of eagles that dominated Europe were falling down slowly. Europe was establishing its postulations, giving way to the origin of World War I and II. Consequently, Reyner did not want to return to France, nor did he want to face the chaos of Europe. For that reason, he decided to settle in Bogotá in order to document all the geographical descriptions he had found during his journeys

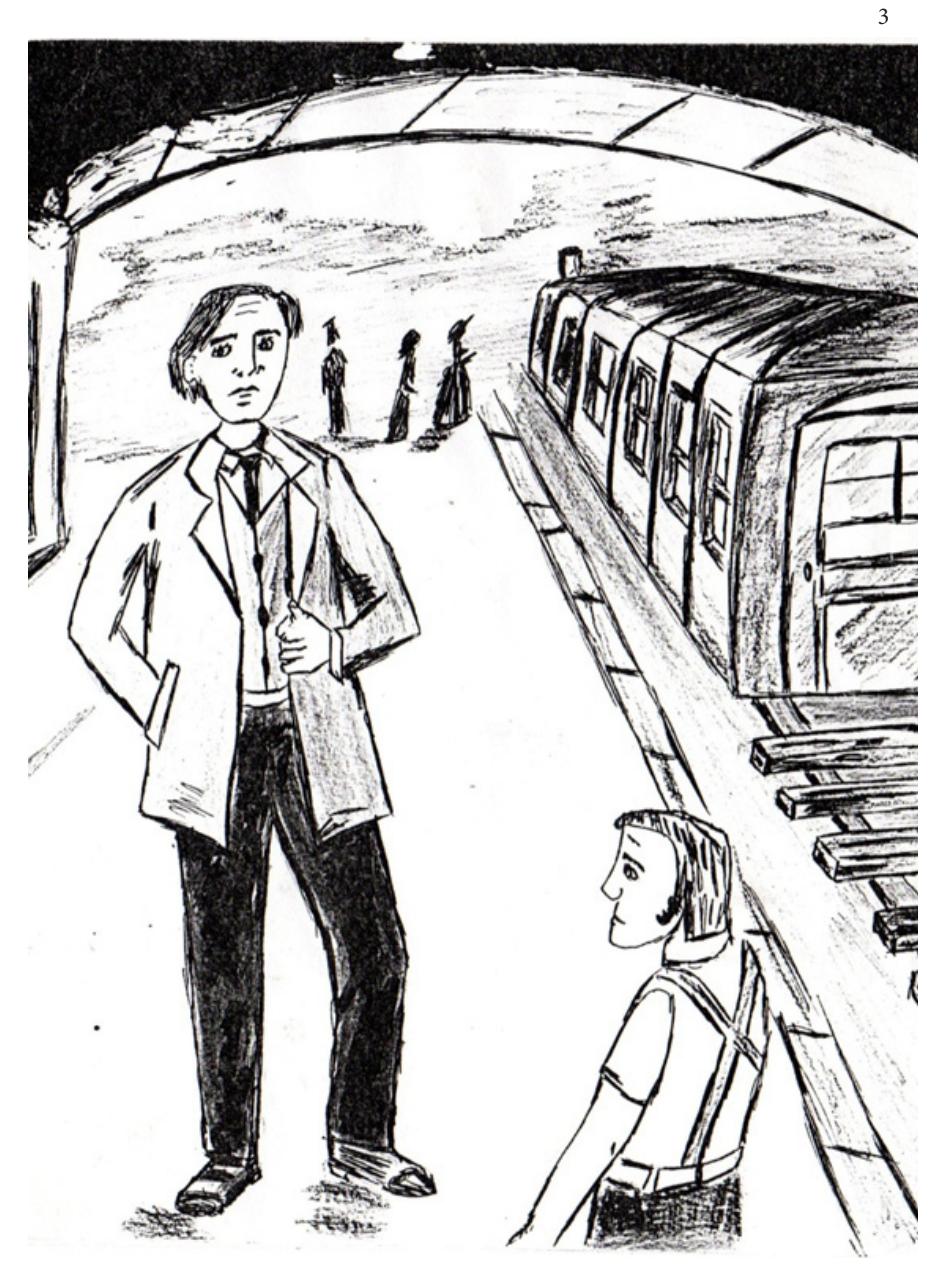




\section{Chapter 2}

The destiny of Victorine was different than that of his older brother. He went to Germany to work as a teacher. Over there, a German household was full of privileges. Victorine was teaching his native language and the world of literature. There, he tutored two children who came from families of high military members. had experienced during the war.

Finally, Victorine painfully returned with his son to his hometown in France because he had no other choice. I did so in order to rediscover his roots and find a place to rest and live quietly in his last days.

Living there, Victorine could feel the pain and the devastation that the two wars brought. Despite of this, Victorine immersed himself in German society and married a prestigious German woman, who supported the principles of her nation. The couple gave birth to a boy named Hans.

The effects of the war followed the members of this family throughout their life. At the end of the second war, the punishers pardoned Victorine and his son. His wife was not as lucky due to the blood origins, and her admiration of the unreasonable leaders.

Hans's parents were very protective of him, and he was never allowed to enlist in the army. He was very well educated with a vast sense of culture. Nothing could erase the nightmares and the bad moments he

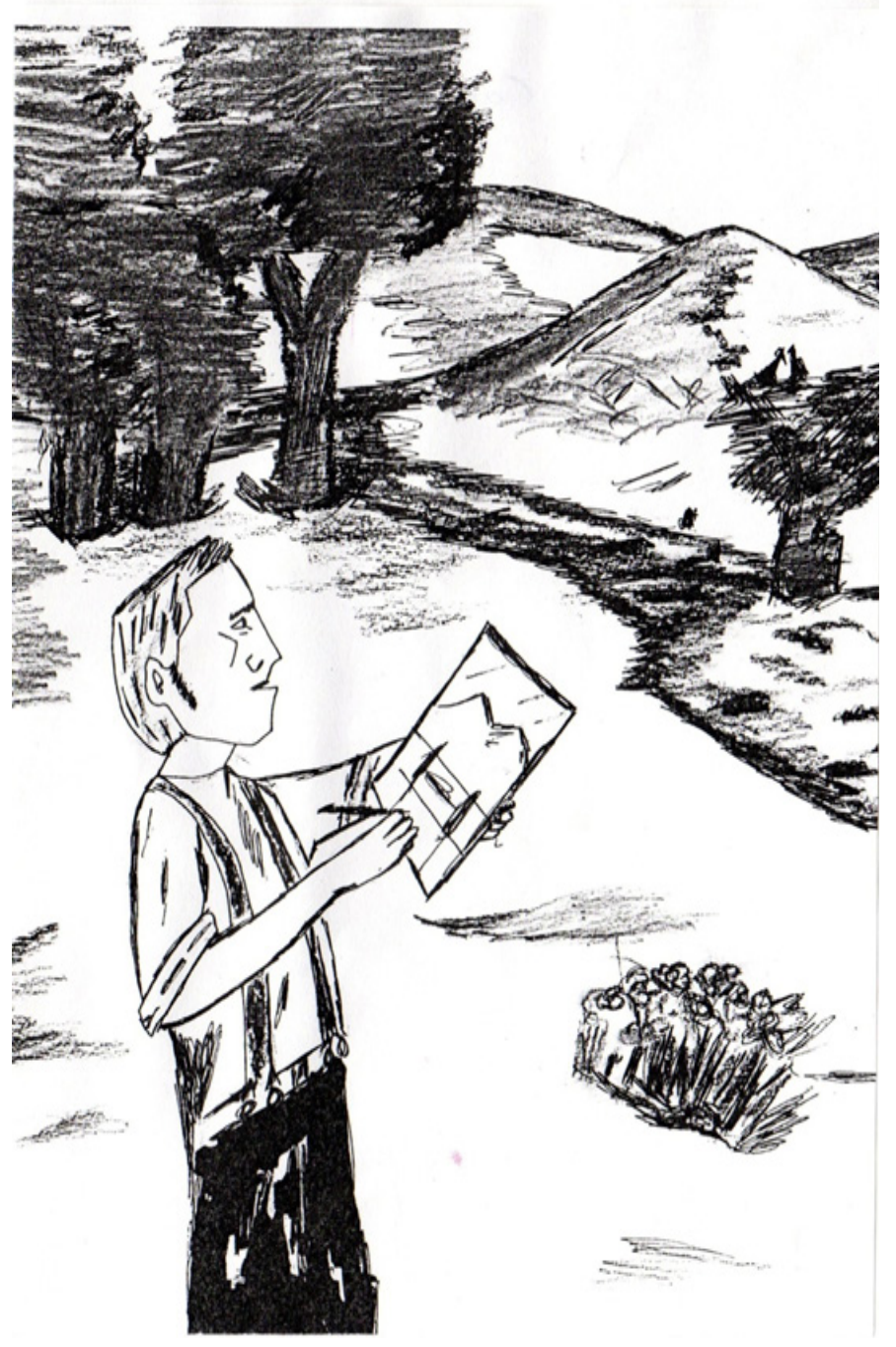




\section{Chapter 3}

A war is the representation of human ambition without limits. This ambition was represented in the devastation of the fight between races and evil minds. This warfare did not measure the distance, weight and volume of its gravity looking the positioning of a superior race. These were the words of Reyner, who was living in Colombia during the first and second world wars.

Unlike his brother, Reyner never married. Reyner was a lonely man, and his job became his passion. Consequently, he never settled in one place. He was always in love with nature and the landscapes he discovered during his life in Colombia. When the world wars finished, he had made all the documentation of the different geographical zones in Colombia. He decided to return to France in order to uncover the origins of his family ties, and to reunite with his brother. He did not know much about his parent's farm, but he was compelled to explore his past life. By this time, he was an old man with a notable reputation in his field. For him, the prestige of being a cartographer was the peak of his dreams and achievements, but inside, he always felt empty. When he was alone, his memories mixed with the heat and cold of the different climates of the country. They were his only friends to share in his success. It was 1945 when he decided to come back to Toulouse to see the place of his childhood and the new Europe after the miserable wars. 


\section{Chapter 4}

After the devastation of the war, the beginning of the emigration conducted Victorine in one direction. He decided to return with his son to his hometown, following the decline of his sorrow. They wanted to start a new life. Victorine was attracted to the abandoned farm of his childhood guided by memories. He lived on his parents' farm, joined with an unexpected forced between father and son, sharing their destinies. They would have another opportunity with the hope of forgetting their problems and fears. On the other hand, Reyner was headed home on a long journey. Nobody would understand his reasons for coming back. Why would a man return to Europe in the middle of such a crisis? He was not a young man anymore, but nothing would change his decision. He had not fought in a war, but now there would be another journey to regret or change his destiny.

On September $13^{\text {th }}, 1945$, Victorine and his son arrived in his hometown village.
One month later, Reyner arrived guided by his memory, but he never planned for the unexpected meeting. The brothers would meet again after fifty-five years. Their conditions were similar, and the stories about their lives were a complete coincidence. Overall, their circumstances separated them, and now their destinies would reunitethem. They could not control their tears, and their first conversation became a complex confession. Their pain and happiness were demonstrated in the long hours of their conversation. Victorine introduced Hans to his uncle, and they connected immediately through all the different kinds of questions they had. Their circumstances had shown them how they had survived in different worlds. Hans told Reyner that he did not have words, only bad experiences to tell. By this time, the symbol of family tied them together. Maybe it was a kind of reconciliation between the past and the lost time where moments had not been shared. 


\section{Chapter 5}

After sharing in the conversation with the two old men, Hans, now 40 years of age, wanted to find the answers about his life. He wanted to find his way through the experiences of the two old men. Moreover, he grew up with two different points of view. One was of his mother, and his inevitable admiration for her leadership and patriotism. The other was of religion, philosophy, art and the straight way of life, built in him by his father.

In those days, his uncle increased his knowledge and fantasies about Colombia with all of the stories. He was especially curious about a territory that Reyner always admired, called Sogamoso. Immediately, Hans's mind was transported to a new continent, a new territory mixed with the teachings of his father.

Hans understood and learned from his uncle's narrations. History and Geography were learned during the chats with his uncle. These chats inspired him to explore. Now, he was interested in the way that the sun shined on the mythical mountains, and of the comfortable climate in the place where he could start again.

Finally, Hans decided to branch out from his European context. He wanted to take advantage of his knowledge and find a peaceful place to finish his last years and erase his bad memories of the wars. His adventurous sense and knowledge mixed with his uncle's teachings. He tried to create a connection with geography and how he would begin a new life in a new country as a foreigner.

After all, Hans was motivated to connect his talent with the new culture in a strange place. He was especially attracted to agriculture for its grains, since they were restricted because of the conflicts in Europe.

Hans thought of a special innovation to bring to the new land, something that would help create a good life.

Eventually, Hans thought of the possibility of leaving France and Europe. He wanted to start a new adventure in his life, as he was tired of the ashes of war. Then, for three years, Hans learned the Spanish language and some fundamental things about Latin American culture in order to start this new experience of his destiny.

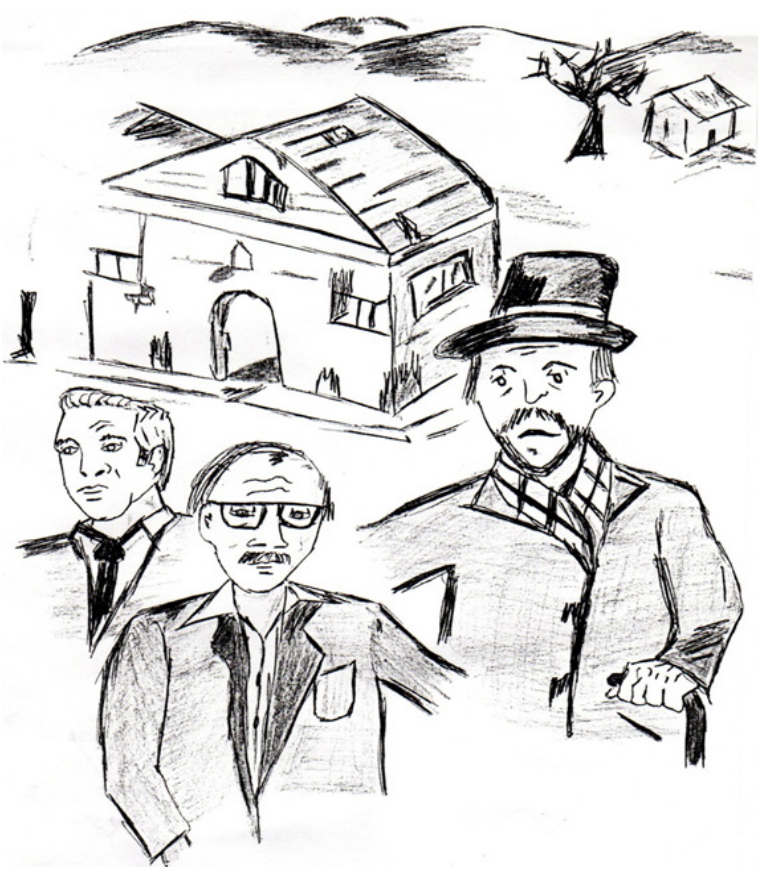




\section{Chapter 6}

Finally, Hans decided to leave France on February 1, 1948, with some money and gold his father and uncle gave him in order to support his travel. It was a tearful goodbye, as they did not except to see each other again. Hans bought a mill with the intention to innovate and help in the growth industry according to the suggestions that his uncle had given him.

A long journey was awaiting Hans in the North of Colombia in Barranquilla. A new culture and experiences were drawn by his uncle in little maps; scales and special dialogues were prepared by his uncle as preparation to live in a South American country. One example was a map that showed the trip across the wonderful Magdalena River to Santa Fe de Bogotá. Inside Colombia, he believed his nightmares of war and persecution would disappear with his new life. Hans was fascinated by the new culture and how everyone admired him wherever he went even though he was a foreigner.

Hans arrived in Bogotá on April 5th. After the long journey, he stayed in a traditional hostel where he took two days to rest. The fascination of the new adventure began in those days; the climate of Bogotá and the colonial style buil- dings captivated him more.

Everything was perfect, but when he was walking in a special area called "La Candelaria," his painful memories returned. He started breathing strangely when he saw people running and breaking the windows everywhere. He thought that the old Germany was following him as he relived his nightmares and confusions from the past wars. A new conflict was waiting for Hans in an unknown country. Immediately, he escaped from "La Candelaria" and ran to his hostel where he was enclosed for five days, hearing bombs, weeping and accepting his misfortune.

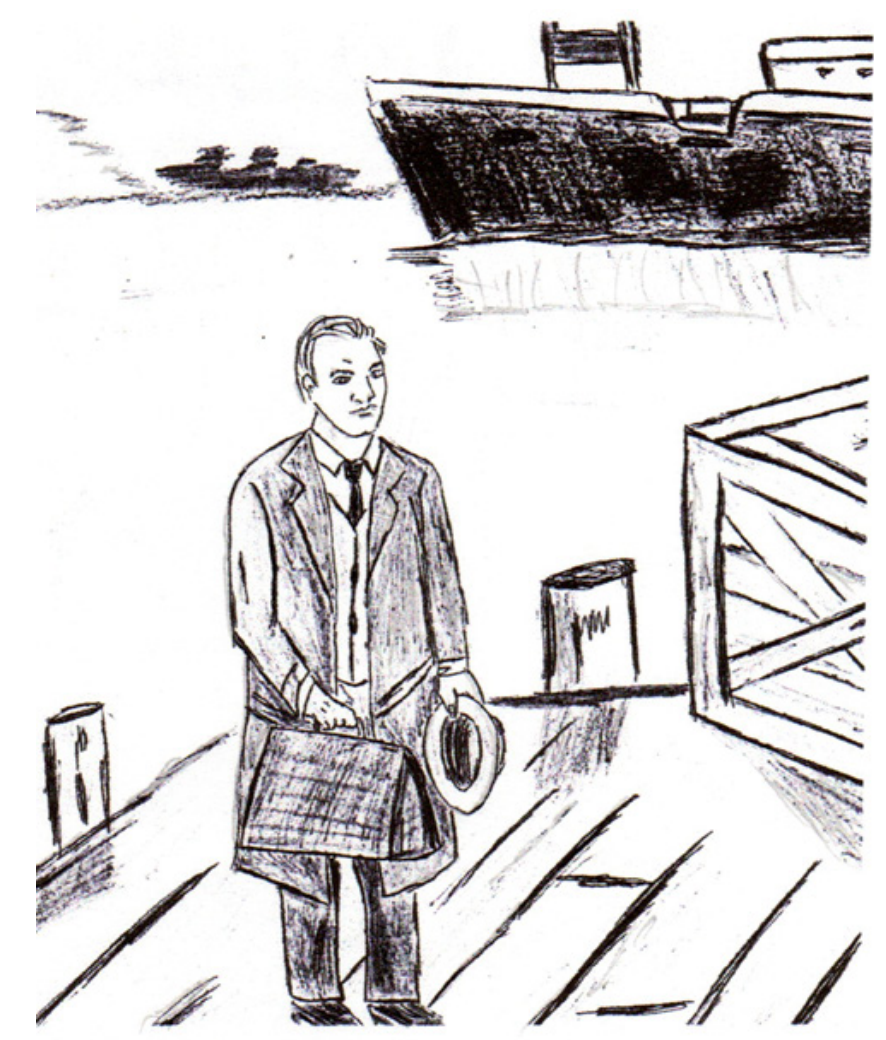




\section{Chapter 7}

After the Bogotazo $0^{4}$, Hans went downtown. Everything was destroyed, and he wondered what the origin of the chaos was. Even though people in his hostel informed him about the unknown causes, he continued to look for answers in other places of Bogotá.

He discovered a new neighborhood full of old coffee shops, where people met to chat about the politics of a destroyed nation, with new visions of power and violence.

He was enjoying a wonderful coffee when a beautiful girl appeared. Emma was a candileja whom he was to fall in love with. Ever since this moment, Emma helped cure his wounds through conversations. This was the beginning of an indescribable passion that would warm the cold and confusing city of Bogotá.

The coffee shop became a space for new expectations. The Colombian woman became part of his new plans. Now Emma and his mill were part of his life, and they were the beginning of the end. The new journey was directed to Sogamoso. In the middle of the popular protests, Hans came to know the differences between Cachiporros $^{5}$ and Chulavitas 6 . Both groups started the violence in Colombia creating the new seed of war in the country. Emma was originally from Bogotá, but she had never been in the old town of Sogamoso, described by uncle Reyner. Hans was expecting a mythical and exciting journey

4 A riot after the assassination of Jorge Eliecer Gaitán

5 Cachiporros were the violent followers of the Liberal political party.

6 Chulavitas were the followers of the Conservative political party through the cold mountains for six hours.

He kept his mill in the hostel until he had found the new place to live. Emma and Hans arrived in Sogamoso, an old town named by the ancient natives as "the town of the sun" in tribute to their sun god. Finally, Hans had arrived at his destination and tried to contact someone who was selling a house with some land in order to start working his mill.

An elderly villager was waiting for him at an old farm called "the Alambra." Hans bought this farm located 5 kilometers outside the town. He went back to Bogotá in order to retrieve his mill. Emma was his companion, and she decided to live with him. In Bogotá, Emma introduced her younger brother Enrique to Hans. Enrique was 25 years old and was a man of luxury. He did not like to work, on the contrary, he enjoyed gambling and drinking. He was the opposite of Emma, as she was honest and kind. Finally, the new couple decided to help Enrique by inviting him to work and live together with them.

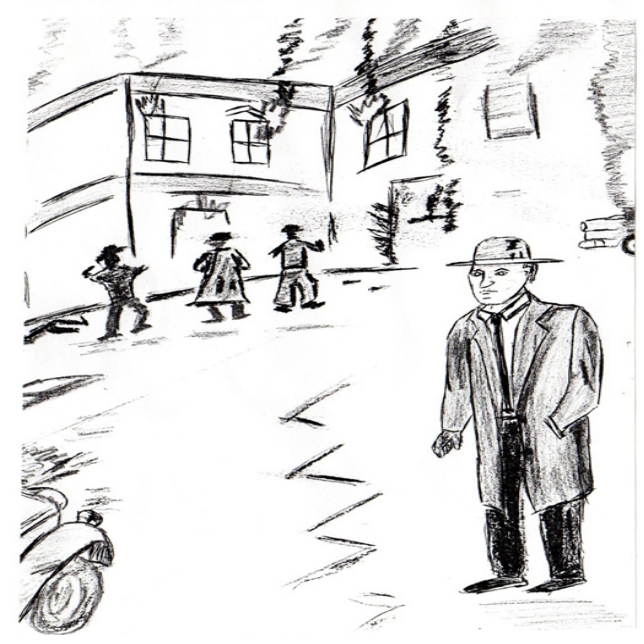




\section{Chapter 8}

The new family was showing its good qualities while living and working on the farm. The new neighbors admired the mill and the progress that it brought to the region. After living there one year, the quality of life had improved for everyone. It was not as difficult as before. Hans was working very hard trying to bring in new customers from around the region, and Emma was making arrangements in the big house.

Enrique worked in the mill with the other workers day after day. There was no rest in the mill because town's people wanted to bring their harvests there. In that same year, Emma became pregnant, and the life of the family would forever change. A new light would be born to reconvert the mill of the Alhambra. Even Enrique changed his laidback lifestyle now that he had a lot of duties and had to follow through with his job in order to become a better brother and worker.

Despite this, Enrique wanted to recover the good old days and memories with his friends, the old Bogotá, and even being in the bohemian streets of the capital city. As Emma was pregnant, Enrique had to cover some of her duties in the mill. He started to change his mind about his

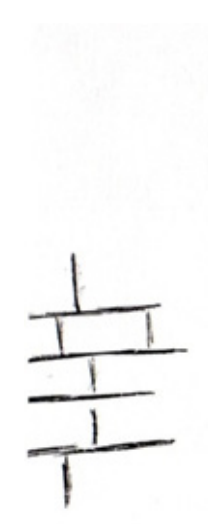

role, starting to believe he had too many responsibilities without any reward. $\mathrm{He}$ began to think that his sister and brother in law controlled him and everything he did, and he did not have any other choices.

Then, the awaited moment when "Alambra" would change forever, came. A beautiful baby girl named Paulina was born. Workers of the mill and neighbors admired the beauty of her mixed races. In the years to come, Hans and Emma's attention would be focused on Paulina, the new joy of their family.

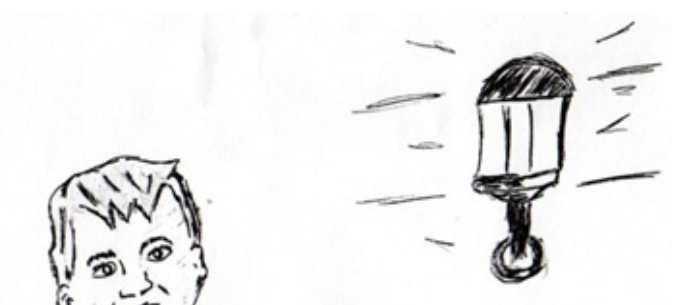

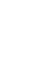




\section{Chapter 9}

Eight years later, Paulina was a wonderful girl admired for her beauty and blonde hair. No other girl was like her. Hans and Emma enjoyed a wonderful marriage and loved each other dearly. This family was the example to follow.

Hans lived a happy life, and his nightmares about the wars would never come back again in that peaceful location. However, around 1958, changes were evident in the old colonial town of Sogamoso.

The new welfare followed with the progress of the first ferrous metallurgy. Reyner had predicted these advances due to the richness of the soil and minerals of the region. Sogamoso made notable progress in economic terms. Thus, new employers brought new people to build their houses and settle in the suburbs.

Meanwhile in the mill, the job was diminished every day as a consequence of the new and old generations of men not wanting to work in the farms. These activities were less sought out, and the mill was facing problems. Workers left their jobs, looking for different opportunities in a new factory. The air was not the same at five in the afternoon. When the sun set, Hans took his daughter and explained the origins of the pink clouds. He was imaginative, and he started to guess the shapes with his daughter as each new cloud expanded. For Paulina, the clouds raised a tender contemplation. Hans and Emma expressed their concerns, but their tranquility was assured for the last good days of their lives.

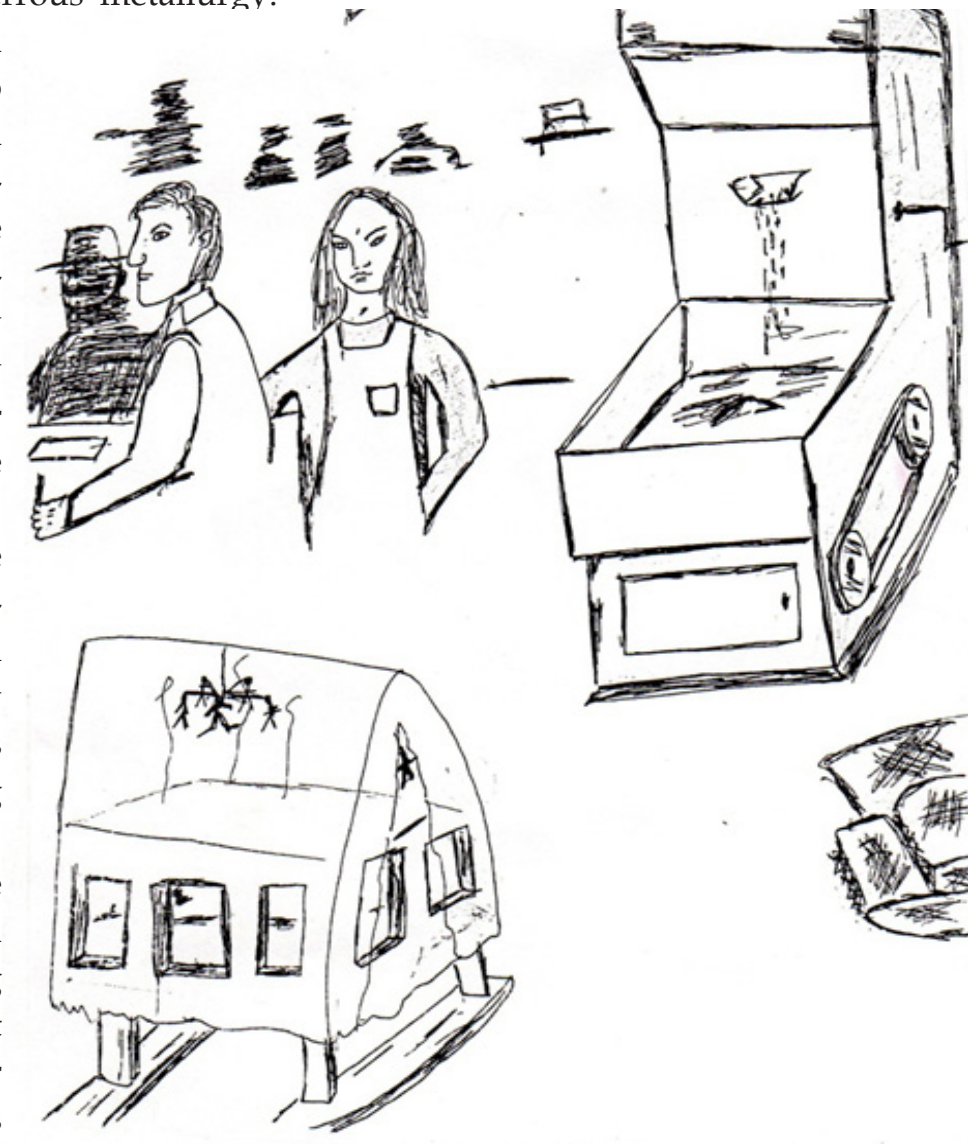




\section{Chapter 10}

Unfortunately, one gray afternoon Emma realized her daughter had disappeared. Her doll and her little carriage were left alone in the yard. Emma shouted and shouted, but Paulina was not around the house. Time passed, and the evening arrived. It was $7 \mathrm{pm}$, and the neighbors and servants were looking for the little blonde girl everywhere. Enrique arrived and started to look for her in the mountains near the house. Emma was desperate by the time Hans returned home. Hans could not believe what was happening. Immediately, he took a lantern and went searching in different directions. The name "Paulina" was heard all through the night. The next day, the police arrived in the mill, and the local radio announced thedisappearance of a beautiful blonde girl. The mill closed during the search, and no one at the mill slept for three days. The chaos continued throughout the next days; there were tears and desperation in the house. Some news arrived from different people, and immediately Hans went to see where the people claimed to have seen the little missing girl. But the search was unsuccessful, and he did not find her. Hans and Emma travelled to nearby locations during those difficult weeks, while Enrique managed the duties of the mill. Emma felt guilty and miserable; she began to doubt everyone, especially her neighbors. She could not sleep smelling the clothes of Paulina. The first month passed and left them with no hope to ever see her again. Hans blamed himself about his daughter's disappearance and his destiny. The mill was full of madness and desperation, the disappearance had transformed their lives and no one could find a solution.

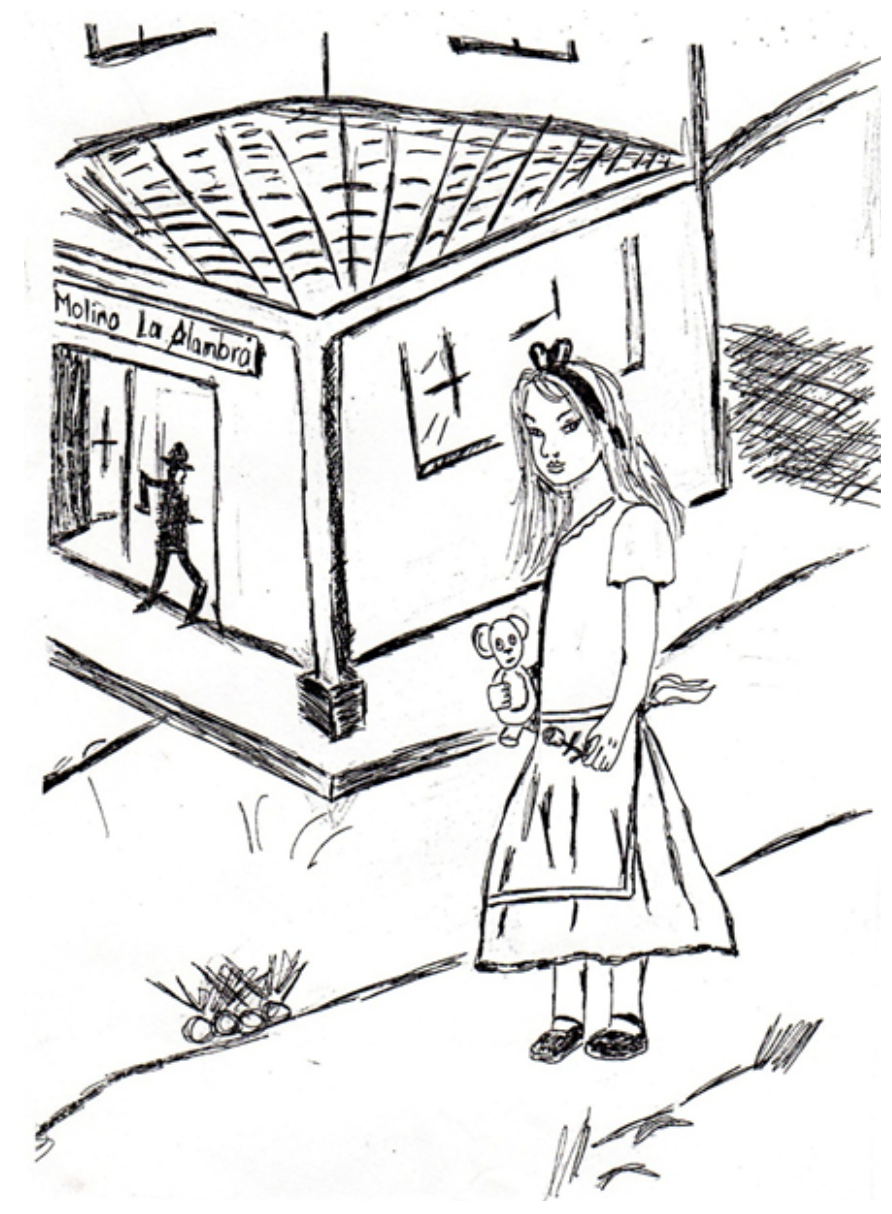




\section{Chapter 11}

After one year, everything was different in the mill. The misery had arrived, customers were no longer coming to the mill. New mills with new technology opened in Sogamoso. Hans was still looking for Paulina, and whenever he heard something about her, he visited that location. He continued traveling in different directions, but no newspaper wanted to publish anything more about the missing child. He looked tired, sick and poorly dressed. Emma's physical beauty had also deteriorated. Even more, she began to experience a mental crisis caused by her daily nightmares. There was not enough food, and rats came to live inside the mill and eat the bags of grains. Enrique tried to look for new jobs; but every day that he earned money, he gambled and drank it.

Sogamoso had a new attraction for the men. The Globo Bar was attracting new people to visit every day. Enrique was anxious to get money in order to spend it there. There were no more conflicts among the family members due to the silence of their guilt. Disappointment and failure caused Hans to fall ill in bed. There was not enough money to pay a doctor. Some good neighbors tended to him, concerned by his terrible cough. Emma was experiencing her more difficult days.
Her madness was with dolls and songs of children playing in those bad, gray days.

As Hans continued to decline, Enrique would ask him for the money he had earned in the mill. Hans could not answer. Hans knew he was on his last breath. At that moment, Enrique told him his cruel testimony about the disappearance of Pauline. He confessed to Hans that he caught, killed and buried her near a brook. Enrique left the house crying and shouting about his bad luck. Pauline was the cause of his anger and jealousy since the moment she was born. Now, he felt the tragedy, neighbors at that location could not understand the terrible shouts of desperation.

The next day, the neighbors had reaized that Hans died. They found his body in the yard. Emma sat singing children songs near a tree where she had found the doll. Nobody saw Enrique again, and since that moment the house turned to ruins. Today there are still remains of the old mill house.

However, the most remarkable occurrence is that every Friday night people can hear cries and little songs emitted by a girl nobody can see.

To my dear father. 1935 - 2013 